\title{
PERILAKU HARGA DAN KETERPADUAN PASAR CABAI MERAH KERITING (Capsicum annuum) DI PROVINSI BENGKULU
}

\author{
PRICE BEHAVIOR AND MARKET INTEGRATION OF RED CHILI \\ (Capsicum annuUm) IN BENGKULU PROVINCE
}

\author{
Sandra, Putri Suci Asriani, dan Witman Rasyid \\ Jurusan Sosial Ekonomi Pertanian Fakultas Pertanian Universitas Bengkulu
}

\begin{abstract}
This research aims to measure of price behavior, market integration and market leader of the red chili in Bengkulu Province. Monthly series of 2006 to 2011 were used as sample data in this analyzing research. The data were from secondary of the monthly average price of red chili. They were obtained from the Central Bureau of Statistics and the Department of Agriculture in Bengkulu Province. The variables which were research included red chili price in the market producer Curup and market consumer Panorama, Minggu, Purwodadi and Ampera. The price behavior applied descriptive statistical analysis, to see the fluctuation of price applied the coefficient of variation formula. The analysis of market integration and marked leader applied the method of co-integration and Granger causality test (Engle and Granger model (1987)). The results of the price behavior showed price of red chili commodity is relative fluctuation. The value of the coefficient of variation $(\mathrm{CV})$ in the consumers area $(\mathrm{CV}=42,35 \%)$ is smaller than in the producer area $(C V=64,41 \%)$. The price of red chili in producer area more fluctuation than the prices in the consumers area. The result of market integration showed a strong level of market integration between market producer Curup and consumer Panorama, Minggu, Purwodadi and Ampera. Besides it, the strong level of integration also between the inter-market consumer Panorama, Minggu, Ampera and Purwodadi. Market leader for commodity red chili in Bengkulu Province is market consumer Panorama.
\end{abstract}

Keywords: Marketing Red Chili, Price Behavior, Market Integration and Market Leader

\section{PENDAHULUAN}

Di Propinsi Bengkulu, cabai merupakan komoditas yang cukup potensial untuk dikembangkan terutama di sentra produksi Kabupaten Rejang Lebong dan Kabupaten Kepahiang. Jenis cabai yang diusahakan oleh masyarakat diantaranya adalah cabai merah keriting. Pada Tabel 1, luas panen cabai merah keriting terluas terdapat di daerah Rejang Lebong sebesar 4.808 ha, dengan

220 | Sandra, Putri Suci Asriani, dan Witman Rasyid. Perilaku Harga .. 
produktivitas sebesar 7,48 ton/hektar dan di kabupaten Kepahiang luas panen sebesar 1.026 ha, dengan produktivitas sebesar 5,78 ton/hektar (BPS, 2011). Peran utama cabai merah keriting yaitu sebagai penyedap makanan atau bumbu masakan baik dikonsumsi dalam rumah tangga maupun sebagai tambahan bahan olahan industri makanan.

Agar terpenuhinya permintaan cabai merah keriting di Propinsi Bengkulu khususnya di daerah-daerah bukan sentra produksi seperti Kota Bengkulu, Seluma, Manna dan Arga Makmur, produksi cabaipun harus selalu dipertahankan maupun ditingkatkan. Namun, pengembangan produk pertanian tidak akan mempunyai arti jika hanya meningkatkan produksi sehingga hasilnya melimpah. Perlu adanya pemasaran yang baik dan harga yang wajar agar petani sebagai produsen mendapatkan insentif dari hasil usaha taninya.

Tabel 1. Luas Panen, Produksi dan Produktivitas Cabai Merah Keriting Menurut Kabupaten/Kota Di Propinsi Bengkulu Pada Tahun 2010

\begin{tabular}{clrcc}
\hline No & Kabupaten/Kota & $\begin{array}{c}\text { Luas Panen } \\
\text { (Ha) }\end{array}$ & $\begin{array}{c}\text { Produksi } \\
\text { (Ton) }\end{array}$ & $\begin{array}{c}\text { Produktivitas } \\
\text { (Ton/Ha) }\end{array}$ \\
\hline $\mathbf{1}$ & Bengkulu Selatan & 108 & 192,2 & 1,78 \\
$\mathbf{2}$ & Rejang Lebong & 4.808 & $35.967,1$ & 7,48 \\
$\mathbf{3}$ & Bengkulu Utara & 393 & 696,0 & 1,77 \\
$\mathbf{4}$ & Kaur & 261 & 317,1 & 1,21 \\
$\mathbf{5}$ & Seluma & 76 & 38,2 & 0,50 \\
$\mathbf{6}$ & Mukomuko & 139 & 681,5 & 4,90 \\
$\mathbf{7}$ & Lebong & 182 & 286,6 & 1,57 \\
$\mathbf{8}$ & Kepahiang & 1.026 & $5.927,9$ & 5,78 \\
$\mathbf{9}$ & Bengkulu Tengah & 231 & $1.020,6$ & 4,42 \\
$\mathbf{1 0}$ & Kota Bengkulu & 50 & 708,0 & 14,16 \\
\hline & Rata-rata & $\mathbf{7 2 7 , 4}$ & $\mathbf{4 . 5 8 3 , 5 2}$ & $\mathbf{4 , 3 6}$ \\
\hline
\end{tabular}

Sumber : Badan Pusat Statistik (2011), Diolah.

Fadhla (2008) menyatakan :

Struktur pemasaran produk pertanian banyak mengarah ke persaingan tidak sempurna dengan fungsi distribusi produk dan penentuan harga didominasi oleh pedagang pengumpul. Sementara perilaku pemasaran tergolong tidak efisien sebagai akibat proses penentuan harga tidak transparan dan adanya kolusi antara pedagang dalam penentuan harga beli di tinggkat petani. Sebagai akibat dari struktur dan perilaku pasar tersebut maka distribusi tidak merata, keuntungan lebih banyak dinikmati oleh pedagang pengumpul, dan bagian harga diterima petani relatif kecil.

Sistem pemasaran cabai merah keriting di Propinsi Bengkulu dapat berjalan secara efisien jika informasi pasar yang diterima memadai. Salah satu informasi pasar yang perlu diketahui yaitu tingkat keterpaduan pasar cabai merah keriting di Propinsi Bengkulu itu sendiri. Sehingga, perubahan harga 
dapat segera diketahui dan pengambilan keputusan oleh produsen yaitu petani dapat dilakukan dengan baik dan tepat.

Kebutuhan akan komoditas cabai merah keriting sering melonjak drastis. Kondisi ini misalnya terjadi pada saat hari-hari besar keagamaan, dampak yang ditimbulkan yaitu kenaikan harga yang cukup tajam. Selain itu, kenaikan harga juga dapat disebabkan oleh kondisi iklim yang tidak menentu yang akan menyebabkan produksi menurun. Walaupun secara kuantitas cabai merah keriting pada konsumen rumah tangga tidak dikonsumsi dalam jumlah besar, namun secara agregat cabai merah keriting cukup besar dibutuhkan oleh masyarakat, sehingga ketika ketidak-ketersediaaan ataupun kurang ketersediaan komoditas cabai merah keriting, serta fluktuasi harga yang tajam dapat menimbulkan keresahan pada masyarakat.

Permintaan cabai merah keriting yang tinggi akan menyebabkan harga naik sedangkan produksi tidak dapat memenuhi keinginan konsumen. Keadaan ini diakibatkan tidak seimbangnya supply-demand, dimana ketidak seimbangan supply-demand tersebut dapat disebabkan oleh beberapa perubahan seperti perubahan teknologi produksi, pertumbuhan populasi atau jumlah konsumen, perubahan tingkat pendapatan perkapita dan musim (Shepherd, 1972 dalam Nidausoleha, 2007).

Dari segi produsen, sikap petani yang misalnya hanya memproduksi cabai merah keriting pada jumlah dan saat tertentu saja akan berpengaruh pada kondisi pasokan dan harga cabaipun pada saat itu akan berfluktuasi. Jika harga cabai merah keriting meningkat produksi cabaipun akan ditingkatkan oleh petani sehingga menyebabkan penurunan harga cabai karena terjadi panen raya. Mengingat cabai mempunyai sifat yang cepat rusak, fluktuasi hargapun tidak dapat dihindari. Sebaliknya, jika pasar dan perkembangan harga cabai merah keriting tidak memberikan insentif pada produsen, maka petani enggan untuk meningkatkan produksinya.

Berdasarkan hal tersebut diatas, penulis tertarik untuk melakukan penelitian mengenai keterpaduan pasar komoditas cabai merah keriting di Propinsi Bengkulu yaitu sejauh mana tingkat perubahan harga di suatu tempat dapat menyebabkan perubahan harga ditempat lain sehingga akan diketahui pasar pemimpin dalam menentukan harga untuk komoditas cabai merah keriting dan bagaimana perilaku harga yang ditimbulkan oleh komoditas cabai merah keriting tersebut.

\section{METODE PENELITIAN}

Metode dasar yang digunakan dalam penelitian ini adalah metode deskriptif yaitu suatu metode dalam meneliti suatu objek yang digambarkan secara sistematis, faktual dan akurat mengenai fakta-fakta, sifat-sifat serta hubungan antar fenomena yang diselidiki dengan jalan mengumpulkan data, menyusun dan kemudian dianalisis (Nazir, 2003). 


\section{Data}

Jenis data yang digunakan dalam penelitian ini adalah data sekunder. Data tersebut yaitu data runtun waktu (time series) bulanan harga cabai merah keriting di berbagai daerah baik daerah produsen dan daerah konsumen di Propinsi Bengkulu sejak tahun 2006 sampai tahun 2011 yang berasal dari Badan Pusat Statistik dan Dinas Pertanian yang ada di Propinsi Bengkulu. Pengumpulan data dalam penelitian ini dilakukan baik dengan cara studi pustaka yaitu metode pengumpulan data yang bersumber dari buku-buku atau literatur-literatur yang berhubungan dengan masalah penelitian, maupun mengambil dan mencatat data dari Badan Pusat Statistik dan Dinas Pertanian yang ada di Propinsi Bengkulu.

\section{Analisis}

Guna mengetahui perilaku harga dilakukan analisis harga bulanan dengan menggunakan analisis statistik deskriptif yang disajikan melalui tabel dan grafik. Sedangkan untuk melihat tingkat fluktuasi harga komoditas cabai merah keriting dapat dihitung dengan menggunakan rumus koefisien variasi. Secara matematis koefisien variasi dapat dihitung dengan menggunakan rumus sebagai berikut :

$$
\mathrm{KV}=\frac{\mathrm{S}}{\overline{\mathrm{x}}} \mathrm{x} 100 \% \quad \mathrm{Dan} \quad \mathrm{S}=\sqrt{\frac{1}{\mathrm{n}-1} \Sigma\left(\mathrm{x}_{\mathrm{i}}-\overline{\mathrm{x}}\right)^{2}} \quad \text { (Santoso, 2003) }
$$

Selanjutnya keterpaduan pasar cabai merah keriting dan pasar pemimpin untuk komoditas cabai merah keriting di Propinsi Bengkulu dianalisis dengan menggunakan model keterpaduan pasar yaitu model analisis Engle dan Granger (1987). Model analisis Engle dan Granger (1987) ini terdiri dari tiga tahap analisis kointegrasi yaitu :

1. Uji akar Unit, untuk mengetahui stasioneritas dari rangkaian variabel

Uji akar unit menggunakan test Dickey-Fuller (DF) dengan 1 periode time lag dan Augmented Dickey-Fuller (ADF) dengan periode time lag lebih dari 1, dengan persamaan sebagai berikut :

$$
\begin{aligned}
& D F \longrightarrow \Delta P_{t}=a+\beta P_{t-1}+\varepsilon_{\mathrm{t}} \\
& A D F \longrightarrow \Delta P_{t}=a+\beta P_{t-1}+\gamma_{2} \Delta P_{t-2}+\varepsilon_{\mathrm{t}}
\end{aligned}
$$

Keterangan $\Delta \mathrm{P}_{\mathrm{t}}$ adalah $\mathrm{P}_{\mathrm{t}}-\mathrm{P}_{\mathrm{t}-1}, \mathrm{P}_{\mathrm{t}}$ adalah harga pada waktu ke-t, $\beta, \gamma$ adalah parameter yang akan diestimasi, $\varepsilon$ adalah variabel kesalahan pengganggu (error term). Dengan hipotesa :

$\mathrm{H}_{0}: \beta=0$, rangkaian data harga $\left(\mathrm{P}_{\mathrm{t}}\right)$ adalah non stasioner

$\mathrm{H}_{1}: \beta \neq 0$, rangkaian data harga $\left(\mathrm{P}_{\mathrm{t}}\right)$ adalah stasioner

2. Tahap kedua adalah test kointegrasi pada variabel kesalahan pengganggunya (residualnya) untuk mengetahui stasioneritas dari rangkaian variabel. Secara statistik dengan persamaan sebagai berikut : 


$$
\begin{aligned}
& P_{1 t}=b_{0}+b_{1} P_{2 t}+e_{t} \\
& \Delta e_{t}=a+\beta e_{t-1}+\gamma_{2} \Delta e_{t-2}+\mu_{t}
\end{aligned}
$$

keterangan $\mathrm{P}_{1}$ adalah harga di pasar -1 dan $\mathrm{P}_{2}$ adalah harga di pasar $-2, \Delta \mathrm{e}_{\mathrm{t}}$ adalah $e_{t}-e_{t-1,} e_{t}$ adalah residu pada waktu ke $t, \beta, \gamma$ adalah parameter yang akan diestimasi, dan $\mu_{\mathrm{t}}$ adalah variabel kesalahan pengganggu (error term). Dengan hipotesa :

$\mathrm{H}_{0}: \beta=0$, rangkaian residu persamaan ko-integrasi $\mathrm{e}_{\mathrm{t}}$ adalah non stasioner

$\mathrm{H}_{1}: \beta \neq 0$, rangkaian residu persamaan ko-integrasi $\mathrm{e}_{\mathrm{t}}$ adalah stasioner

Selanjutnya untuk menguji rangkaian data harga dan rangkaian residu pada persamaan kointegrasi stasioner atau tidak digunakan uji $t$ sebagai berikut :

$$
t_{\text {hitung }}=\frac{\beta_{i}}{\operatorname{Se}\left(\beta_{i}\right)}
$$

Dimana $\beta_{i}$ adalah parameter yang diestimasi, $\operatorname{Se} \beta_{i} \quad$ adalah Standard error dari Parameter yang diestimasi.

Kriteria pengujian :

$\mathrm{H}_{0}$ diterima apabila $\mathrm{t}_{\text {hitung }}<\mathrm{t}_{\text {Tabel }}$ $\mathrm{H}_{1}$ diterima apabila $\mathrm{t}_{\text {hitung }}>\mathrm{t}_{\text {Tabel }}$

Tahap kedua ini bertujuan untuk mengetahui tingkat keterpaduan pasar (Integrasi Pasar) dari kombinasi pasar cabai merah keriting di Propinsi Bengkulu. Dalam sebuah sistem pasar yang terintegrasi secara efisien akan terjadi korelasi (hubungan) yang positif di antara lokasi pasar yang berbeda sepanjang waktu. Koefisien korelasi tersebut secara langsung mengukur seberapa dekat harga dari suatu komoditas bergerak bersamasama dalam lokasi pasar yang berbeda.

3. Tahap ketiga Uji Granger Causality untuk mengetahui pasar leading (Pasar Pemimpin) komoditas cabai merah keriting di Propinsi Bengkulu dengan model sebagai berikut :

$$
\begin{aligned}
& \Delta P_{1 t}=b_{01}+b_{02} P_{1(t-1)}+b_{03} P_{2(t-1)}+\sum \partial_{i}\left(\Delta P_{1(\mathrm{t}-i)}\right)+\sum \delta_{i} \Delta P_{2(\mathrm{t}-i)}+\varepsilon_{\mathrm{t}} \\
& \Delta P_{2 t}=b_{11}+b_{12} P_{2(t-1)}+b_{13} P_{1(t-1)}+\sum \Phi_{i}\left(\Delta P_{2(\mathrm{t}-i)}\right)+\sum \lambda_{i} \Delta P_{1(\mathrm{t}-i)}+\varepsilon_{\mathrm{t}}
\end{aligned}
$$

dimana $\Delta \mathrm{P}_{1 \mathrm{t}}$ adalah $\mathrm{P}_{1 \mathrm{t}}-\mathrm{P}_{1(\mathrm{t}-1) \text {; }}$ dan $\Delta \mathrm{P}_{2 \mathrm{t}}$ adalah $\mathrm{P}_{2 \mathrm{t}}-\mathrm{P}_{2(\mathrm{t}-\mathrm{1}),} \quad b_{02}, \quad b_{03}, \quad \delta, \quad \partial$ adalah parameter yang akan diestimasi dari $\Delta \mathrm{P}_{1 \mathrm{t}}, \quad b_{12}, b_{13}, \Phi, \lambda$ adalah parameter yang akan diestimasi dari $\Delta \mathrm{P}_{2 \mathrm{t}}$, dan $\varepsilon_{\mathrm{t}}$ adalah error term

Dengan mengasumsikan bahwa $\mathrm{P}_{1}$ adalah harga di pasar konsumen dan $\mathrm{P}_{2}$ adalah harga di pasar produsen pada waktu ke $\mathrm{t}$, maka berdasarkan persamaan diatas disusun dua buah hipotesa untuk mendeterminasi hubungan Granger Causality:

$\mathrm{H}_{0}: b_{03}=\delta=0$, Harga di pasar produsen tidak berpengaruh pada 
harga di pasar konsumen

$b_{13}=\lambda=0$, Harga di pasar konsumen tidak berpengaruh pada harga di pasar produsen

$\mathrm{H}_{1}: b_{03} \neq \delta \neq 0$, Harga di pasar produsen berpengaruh pada harga di pasar konsumen

$b_{13} \neq \lambda \neq 0$, Harga di pasar konsumen berpengaruh pada harga di pasar produsen

Keputusan apakah harga di pasar produsen mempengaruhi harga di pasar konsumen dan sebaliknya harga di pasar konsumen mempengaruhi harga di pasar produsen digunakan uji F. Apabila $F_{\text {hitung }}>F_{T a b e l}$. Hasil uji Granger Causality dapat mendeteksi adanya hubungan antar variabel, atau paling tidak hubungan satu arah. Nilai $F$ hitung dapat diperoleh dari persamaan sebagai berikut :

$$
F(P, d f)=\frac{\left(R S S_{\text {reduce }}-R S S_{\text {complete }}\right) / P}{\left(R S S_{\text {complete }}\right) / d f}
$$

dimana $d f$ adalah derajat bebas, $\mathrm{P}$

RSS adalah residual sum square

adalah variabel independen, dan

Selanjutnya apabila terjadi hubungan dua arah, maka untuk mendeteksi pasar yang leading diuji dengan uji t. Hipotesisnya :

$\mathrm{H}_{0}: b_{13}<b_{03}$, Harga di pasar $\mathrm{P}_{2}$ (pasar produsen) mendominasi pasar $\mathrm{P}_{1}$ (pasar konsumen)

$\mathrm{H}_{1}: b_{13}>b_{03}$, Harga di pasar $\mathrm{P}_{1}$ (pasar konsumen) mendominasi pasar $\mathrm{P}_{1}$ (pasar produsen)

Kriteria pengujian adalah $t_{\text {hitung }}>t_{\text {Tabel }}$ yang berarti menolak $\mathrm{H}_{0}$ dan menerima $\mathrm{H}_{1}$ yaitu harga di pasar konsumen dikatakan mendominasi harga di pasar produsen.

Pada penelitian ini proses pelaksanaan analisis dilakukan dengan program Eviews. Eviews adalah program komputer yang digunakan untuk mengolah data statistik dan data ekometrika dan dapat digunakan untuk menyelesaikan masalah-masalah berbentuk time series. Cross section, maupun data panel (Winarno, 2007).

\section{HASIL DAN PEMBAHASAN}

\section{Analisis Perilaku Harga Cabai Merah Keriting}

Perkembangan harga cabai merah keriting di daerah produsen dan konsumen relatif berfluktuasi. Dari hasil analisis perilaku harga dengan pendekatan grafik bulanan cabai merah keriting selama periode tahun 20062011, baik di pasar produsen maupun di pasar konsumen menunjukkan pola 
pergerakan yang sama (Gambar 1). Apabila di daerah produsen tinggi, begitu juga di daerah konsumen atau sebaliknya. Nilai koefisien variasi di daerah konsumen lebih kecil dibandingkan nilai koefisien variasi di daerah produsen (KVKonsumen 42,35 \% < KV Produsen 64,41 \%). Hal ini menunjukkan bahwa harga cabai merah keriting di daerah konsumen relatif stabil dibandingkan dengan harga di daerah produsen, dengan kata lain bahwa harga cabai merah keriting di daerah produsen lebih berfluktuasi dari pada harga di daerah konsumen.

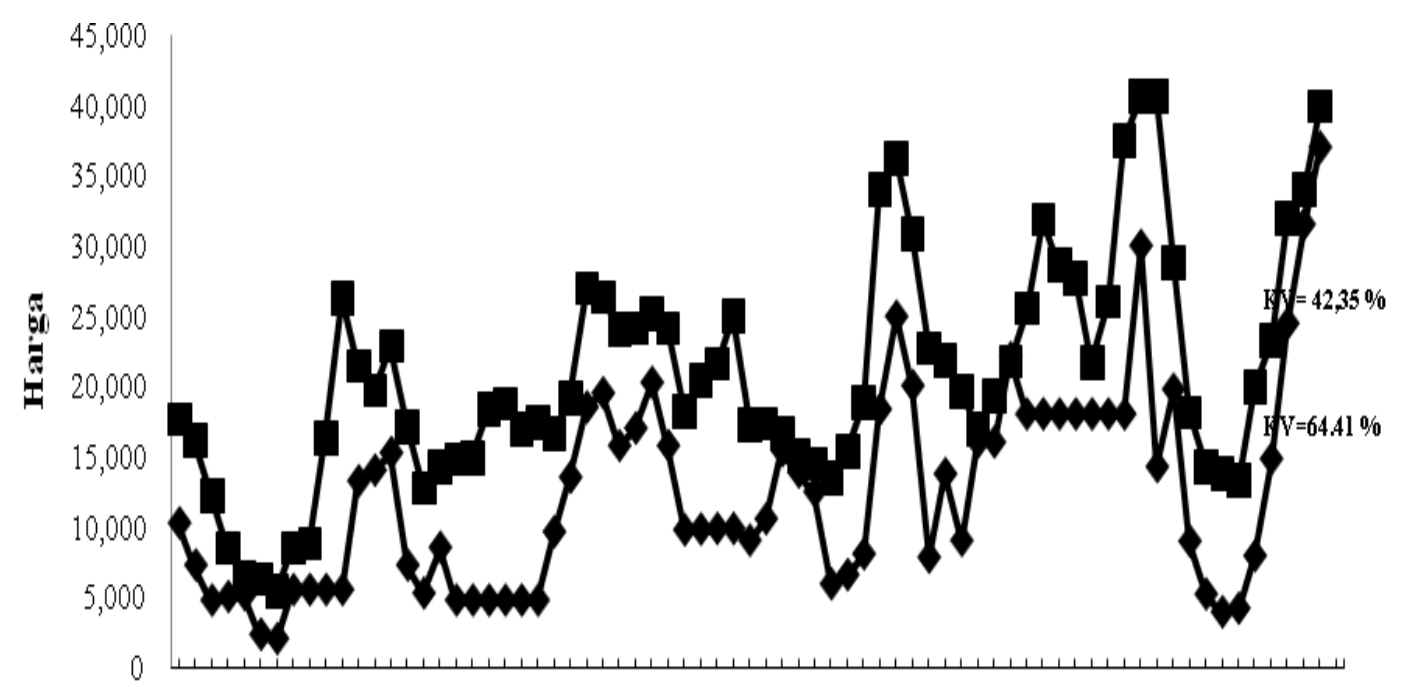

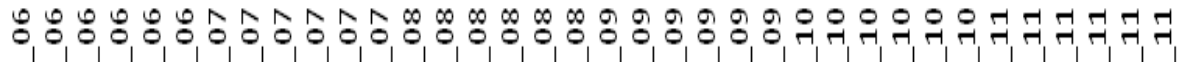

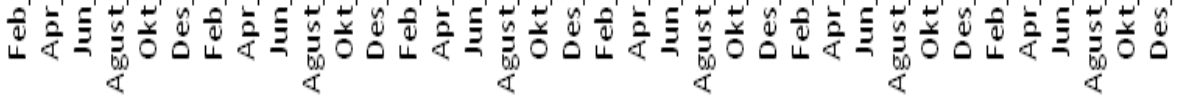

$\rightarrow$ Pasar Produsen $\rightarrow$-Pasar Konsımen

Gambar 4. Perkembangan Harga Cabai Merah Keriting di Pasar Produsen dan Pasar Konsumen Propinsi Bengkulu

Sumber : Hasil Analisis Data Sekunder (2011).

Menurut Nidausoleha (2007), koefisien variasi (KV) menggambarkan fluktuasi (simpangan terhadap rata-rata), dimana fluktuasi tersebut menggambarkan risiko, dari grafik tersebut menunjukkan bahwa pasar produsen lebih berisiko dibandingkan pasar konsumen. Artinya, risiko dalam pemasaran cabai merah keriting di pasar produsen tinggi, karena informasi harga yang tidak menentu (harga berfluktuasi). Risiko tersebut, misalnya kurangnya kemampuan dalam menentukan harga jual. Selain itu, keadaan ini juga mengambarkan bahwa tidak seimbangnya supply-demand untuk komoditas cabai merah keriting. Menurut Anindita (2004), "fluktuasi harga komoditas pertanian disebabkan oleh tiga alasan, yaitu karena naik turunnya permintaan (fluctuation in demand), naik turunnya penawaran (fluctuation in supply), dan experimentasi dalam proses penentuan harga." 
Dari hasil analisis perilaku harga berdasarkan tempat, perkembangan harga dalam enam tahun terakhir (Tabel 2) menunjukkan harga di pasar produsen Curup relatif berfluktuasi dibandingkan pasar-pasar konsumen di Propinsi Bengkulu. Nilai KV di pasar produsen Curup $(29,8 \%)$ pada tahun 2008 lebih besar dari pasar Panorama (13,24\%), Minggu (21,42\%), Ampera (16,71\%) dan Purwodadi (12,65\%). Selain itu, pada tahun 2011 perilaku harga cabai merah keriting juga menunjukkan hal yang sama, nilai KV pasar Curup $(68,87 \%)$ lebih besar dari pada nilai KV pasar konsumen Panorama (42,12\%), Minggu (60,62\%), Ampera (62,48\%) dan Purwodadi (21,20\%). Nilai KV yang tinggi juga menggambarkan resiko harga di pasar. Resiko ini menggambarkan harga cabai merah keriting yang tidak ditransmisikan secara sempurna dan menandakan informasi harga cabai merah keriting di setiap pasar konsumen tidak diterima dengan baik oleh pasar produsen Curup. Perilaku harga cabai merah keriting di pasar konsumen yaitu pasar Panorama, pasar Minggu, pasar Ampera dan pasar Purwodadi pada tahun tersebut relatif lebih stabil jika dibandingkan dengan pasar produsen Curup.

Tabel 2. Perilaku Harga Cabai Merah Keriting Tahun 2006-2011 di masingmasing Pasar

\begin{tabular}{llrrrrrr}
\hline \multirow{2}{*}{ No } & \multicolumn{1}{c}{ Uraian } & \multicolumn{7}{c}{ Tahun } \\
\cline { 2 - 7 } & \multicolumn{2}{c}{$\mathbf{2 0 0 6}$} & $\mathbf{2 0 0 7}$ & $\mathbf{2 0 0 8}$ & $\mathbf{2 0 0 9}$ & $\mathbf{2 0 1 0}$ & $\mathbf{2 0 1 1}$ \\
\hline 1 & Pasar Curup & & & & & & \\
& Rerata Harga(Rp) & 5.922 & 7.667 & 14.094 & 12.743 & 16.896 & 16.828 \\
\multirow{2}{*}{2} & Koefisien Variasi(\%) & 49,39 & 53,71 & 29,8 & 46,85 & 18,58 & 68,87 \\
& Pasar Panorama & & & & & & \\
& Rerata Harga(Rp) & 12.606 & 19.588 & 22.083 & 20.888 & 27.158 & 25.104 \\
& Koefisien Variasi(\%) & 52,19 & 30,52 & 13,24 & 52,81 & 35,98 & 42,12 \\
3 & Pasar Minggu & & & & & & \\
& Rerata Harga(Rp) & 12.996 & 16.872 & 23.250 & 22.665 & 28.421 & 27.525 \\
& Koefisien Variasi(\%) & 51,63 & 22,02 & 21,42 & 37,08 & 32,68 & 60,62 \\
4 & Pasar Ampera & & & & & & \\
& Rerata Harga(Rp) & 11.792 & 12.625 & 22.167 & 16.417 & 18.858 & 25.875 \\
& Koefisien Variasi(\%) & 52,46 & 26,97 & 16,71 & 59,87 & 15,35 & 62,48 \\
5 & Pasar Purwodadi & & & & & & \\
& Rerata Harga(Rp) & 13.542 & 20.583 & 22.942 & 23.979 & 24.875 & 27.650 \\
& Koefisien Variasi(\%) & 65,64 & 17,01 & 12,65 & 22,33 & 29,3 & 21,20 \\
\hline
\end{tabular}

Sumber : Hasil Analisis Data Sekunder (2011).

Analisis perilaku harga berdasarkan tempat di pasar konsumen menunjukkan bahwa perkembangan harga dalam tiga tahun terakhir kencenderungan harga di pasar Ampera relatif berfluktuasi diikuti pasar Panorama dan Minggu. Nilai KV pasar Ampera pada tahun 2009 (59,87\%) lebih besar jika dibandingkan dengan pasar konsumen Panorama (52,81\%) dan pasar Minggu (37,08\%). Pada tahun 2011, Nilai KV pasar Ampera (62,48\%) juga lebih 
besar jika dibandingkan dengan pasar konsumen Panorama (42,12\%) dan pasar Minggu (60,62\%). Sedangkan pada tahun 2010, harga cabai merah keriting di Ampera relatif stabil. Berbeda dengan pasar Ampera, Panorama dan Minggu, dilihat dari nilai KV pasar Purwodadi dalam tiga tahun terakhir memiliki kecenderungan harga stabil 2009 (22,33\%), 2010 (29,3\%) dan 2011 (21,20\%). Resiko dari fluktuasi harga di pasar-pasar konsumen tersebut yaitu tidak mampunya pedagang dalam menentukan harga, selain itu hal ini juga menggambarkan harga tidak ditransmisikan secara sempurna dan informasi harga antara pasar konsumen tidak diterima dengan baik oleh setiap pasar konsumen. Nilai KV pada pasar Purwodadi pada setiap tahunnya memiliki kecenderungan lebih kecil dibandingkan dengan pasar konsumen lainnya, ini menunjukkan harga di pasar ini relatif lebih stabil dibandingkan pasar konsumen lainnya. Selain itu, pasar Purwodadi juga memiliki kecenderungan harga rata-rata yang tinggi dibandingkan dengan pasar-pasar konsumen yang lainnya. Kondisi ini menggambarkan bahwa informasi harga dapat diterima dengan baik oleh pasar Purwodadi.

\section{Analisis Keterpaduan Pasar Cabai Merah Keriting}

\section{Uji Stasionaritas Harga Cabai Merah Keriting}

Analisis stasioner akar unit untuk setiap data harga bulanan cabai merah keriting di kelima pasar yaitu pasar Curup, pasar Panorama, pasar Minggu, pasar Ampera dan pasar Purwodadi digunakan model analisis yaitu Augmented test Dicket-Fuller (ADF). Untuk mengetahui data itu stasioner dapat dilakukan dengan cara membandingkan nilai t-statistik dengan nilai kritis MacKinnon, apabila nilai t-statistik (ADF Test) lebih besar dari nilai kritis MacKinnon pada taraf signifikansi yang telah ditentukan maka akan menolak $\mathrm{H} 0$ dan menerima $\mathrm{H} 1$ yang berarti data harga adalah stasioner.

Tabel 3. Hasil Uji Akar Unit (ADF Test) Data Harga Bulanan Cabai Merah Keriting Tahun 2006-2011

\begin{tabular}{lcc}
\hline \multirow{2}{*}{ Harga } & \multicolumn{2}{c}{ Uji Akar Unit Tingkat Level } \\
\cline { 2 - 3 } & Lag & ADF test (t-statistik) \\
\hline Pasar Curup & 2 & $-3,0000^{* *}$ \\
Pasar Panorama & 0 & $-3,6015^{* * *}$ \\
Pasar Minggu & 1 & $-3,6798^{* * *}$ \\
Pasar Ampera & 0 & $-3,2029^{* *}$ \\
Pasar Purwodadi & 0 & $-3,2568^{* *}$ \\
\hline Nilai Kritis MacKinnon & $1 \%$ & $-3,5256^{* * *}$ \\
& $5 \%$ & $-2,9029^{* *}$ \\
\hline
\end{tabular}

Sumber : Hasil Analisis Data Sekunder (2011)

Keterangan *** Signifikan pada a $1 \%$, ** Signifikan pada a $5 \%$ 
Hasil Uji Akar Unit (ADF Test) di kelima pasar cabai merah keriting dapat dilihat pada Tabel 3. Dari hasil estimasi diperoleh nilai t-statistik pasar Curup lebih besar dari nilai kritis MacKinnon pada taraf signifikansi (a) $5 \%$, sehingga dapat dinyatakan bahwa H0 ditolak. Artinya data harga cabai merah keriting pada pasar tersebut adalah stasioner pada tarap kepercayaan 95\%. Sama halnya dengan pasar Produsen Curup, untuk pasar Konsumen Ampera dan Purwodadi memiliki nilai t-statistik lebih besar dari nilai kritis MacKinnon pada taraf signifikansi (a) 5\%, sehingga dapat dinyatakan bahwa H0 ditolak HI diterima artinya data harga cabai merah keriting pada pasar-pasar tersebut adalah stasioner pada tarap kepercayaan 95\%. Sedangkan pasar Konsumen Panorama dan Minggu memiliki nilai t-statistik lebih besar dari nilai kritis MacKinnon masing-masing yaitu $(-3,6015>-3,5256)$ dan $(-3,6798>-3,5256)$ pada tarap signifikansi (a) 1\%, sehingga dapat dinyatakan bahwa $\mathrm{H} 0$ ditolak $\mathrm{HI}$ diterima artinya data harga cabai merah keriting pada pasar-pasar tersebut adalah stasioner pada tarap kepercayaan $99 \%$.

Data serial waktu seringkali mengandung akar unit, oleh sebab itu diperlukan pengujian stasionaritas. Tujuan uji ini adalah agar tidak menimbulkan kelancungan regresi dalam hasil analisis datanya (Winarno, 2007). Regresi lancung adalah situasi dimana hasil regresi menunjukkan koefisien regresi yang signifikan secara statistik dan nilai koefisien determinasi yang tinggi namun hubungan antar variabel di dalam model tidak saling berhubungan (Widarjono, 2007). Dari hasil uji tersebut diketahui data harga bulanan cabai merah keriting pada kelima pasar adalah stasioner dan bebas dari kelancungan regresi, sehingga selanjutnya dapat dilakukan uji kointegrasi harga.

\section{Uji Kointegrasi}

Uji Kointegrasi dilakukan dengan meregresi variabel harga antar pasar satu dengan yang lainnya. Kemudian diuji apakah residu persamaan regresi tersebut mengandung akar unit atau tidak dengan menggunakan DF Test pada tingkat level, jika tidak mengandung akar unit maka residu persamaan tersebut adalah stasioner dan dapat dikatakan bahwa antar variabel yang diregresi adalah saling berkointegrasi atau berketerpaduan. Dari hasil uji tersebut terdapat tingkat signifikansi (a) 1\%, 5\% dan 10\%, yang masing-masing menunjukkan tingkat keterpaduan yang kuat, sedang dan lemah. Tahap kointegrasi ini bertujuan untuk mengetahui tingkat keterpaduan pasar cabai merah keriting di Propinsi Bengkulu. Tingkat keterpaduan pasar pada penelitian ini terdiri dari dua yaitu keterpaduan pasar cabai merah keriting antara pasar produsen dan pasar konsumen dan keterpaduan pasar antar pasar konsumen.

\section{Uji Kointegrasi Antara Pasar Produsen dan Pasar Konsumen}

Model persamaan kointegrasi ini adalah antara pasar produsen Curup dengan pasar konsumen yaitu pasar Panorama, pasar Minggu, pasar Ampera 
dan pasar Purwodadi. Uji akar unit residual persamaan kointegrasi dengan model DF Test pada tingkat level I(0) dapat dilihat pada Tabel 4.

Tabel 4. Hasil Uji akar Unit (DF Test level I(0)) Residual Persamaan Kointegrasi Hubungan antara Pasar Produsen dan Konsumen

\begin{tabular}{lcccc}
\hline Ke & $\begin{array}{c}\text { Pasar } \\
\text { Panorama }\end{array}$ & $\begin{array}{c}\text { Pasar } \\
\text { Minggu }\end{array}$ & $\begin{array}{c}\text { Pasar } \\
\text { Ampera }\end{array}$ & $\begin{array}{c}\text { Pasar } \\
\text { Purwodadi }\end{array}$ \\
\hline Pasar Curup & $-4,8434^{* * *}$ & $-5,9487^{* * *}$ & $-5,5350^{* * *}$ & $-5,4742^{* * *}$ \\
\hline Nilai Kritis ${ }^{2}$ MacKinnon & $\begin{array}{r}1 \% \\
5 \%\end{array}$ & & $-3,5300$ & \\
\hline
\end{tabular}

Sumber : Hasil Analisis Data Sekunder (2011)

Keterangan *** Signifikan pada a $1 \%, * *$ Signifikan pada a $5 \%$

Dari hasil estimasi keterpaduan pasar antar pasar Curup dan Panorama diperoleh nilai t-statistik $(-4,8435)$ yang lebih besar dari nilai kritis MacKinnon (3,5300) pada tarap signifikansi (a) $1 \%$ sehingga akan menolak Ho dan menerima $\mathrm{H} 1$ yang berarti rangkaian data harga adalah stasioner pada tarap kepercayaan 99\%, artinya terdapat keterpaduan pasar yang kuat pada kombinasi pasar tersebut. Tingkat keterpaduan pasar yang kuat juga terjadi pada kombinasi pasar Curup dan Minggu dengan nilai t-statistik $(-5,9487)$ yang lebih besar dari nilai kritis MacKinnon $(-3,5300)$ pada tarap signifikansi (a) $1 \%$ sehingga akan menolak Ho dan menerima $\mathrm{H} 1$ yang berarti rangkaian data harga adalah stasioner pada tarap kepercayaan 99\%. Sama halnya kombinasi pasar sebelumnya, kombinasi pasar Curup dan Ampera dan Pasar Curup dan Purwodadi memiliki hubungan keterpaduan pasar yang kuat nilai t-statistik yang lebih besar dari nilai kritis MacKinnon masing-masing yaitu (-5,5350 > $3,5300)$ dan $(-5,4742>-3,5300)$ pada tarap signifikansi (a) $1 \%$ sehingga akan menolak Ho dan menerima H1 yang berarti rangkaian data harga adalah stasioner pada tarap kepercayaan 99\%, artinya terdapat keterpaduan pasar yang kuat pada kombinasi pasar tersebut

Tingkat keterpaduan pasar cabai merah keriting antara pasar produsen dan pasar konsumen dilihat dari rangkaian data harga dan rangkaian residu pada persamaan kointegrasi yang stasioner. Keterpaduan pasar yang kuat (dilihat dari tingkat siknifikansi a $1 \%$ ) antara pasar produsen Curup dengan pasar konsumen yaitu pasar Panorama, pasar Minggu, pasar Ampera dan pasar Purwodadi menunjukkan ada hubungan antara pasar satu dengan pasar yang lainnya dalam hal perubahan harga dan transmisi harga sehingga naik turunnya harga cabai merah keriting di pasar produsen akan mempengaruhi harga cabai merah keriting di pasar konsumen, begitupun sebaliknya naik turunnya harga cabai merah keriting di pasar konsumen akan mempengaruhi harga cabai merah keriting di pasar produsen. Tingkat keterpaduan pasar yang kuat disebabkan ketidakseimbangan produksi antar daerah. Kabupaten Rejang Lebong 
merupakan sentra produksi cabai merah keriting di Propinsi Bengkulu dan jika produksi melimpah akan menyebabkan harga cabai merah keriting turun, sedangkan daerah konsumsi seperti Kota Bengkulu, Kabupaten Bengkulu Selatan dan Bengkulu Utara hanya memiliki kebun cabai merah keriting perorangan yang hanya dipasarkan di pasar lokal dan tidak cukup untuk memenuhi permintaan sehingga harga cabai merah keriting di daerah ini tinggi. Kondisi ini akan menyebabkan daerah sentra produksi menjual cabai merah keriting ke daerah konsumsi (pemasaran antar tempat) sehingga akan menyebabkan integrasi pasar yang tinggi. Pasar-pasar yang mempunyai surplus komoditas dengan pasar-pasar yang defisit atau kekurangan komoditas akan melakukan perdagangan antar daerah dengan integrasi pasar yang tinggi dari pada kedua daerah tersebut mengalami surplus atau defisit saja (Goletti, Ahmed, dan Farid dalam Goletti dan Tsigas, (1996) dalam Anindita, (2004)).

\section{Uji Kointegrasi Antar Pasar Konsumen}

Model persamaan kointegrasi ini adalah antar pasar konsumen di Propinsi Bengkulu, dengan kombinasi pasar konsumen yaitu pasar Panorama dan Minggu, Panorama dan Ampera, Panorama dan Purwodadi, Minggu dan Panorama, Minggu dan Ampera, Minggu dan Purwodadi, Ampera dan Panorama, Ampera dan Minggu, Ampera dan Purwodadi, Purwodadi dan Panorama, Purwodadi dan Minggu, dan pasar Purwodadi dan Ampera. Hasil estimasi uji akar unit (DF Test level I(0)) terhadap residual persamaan kointegrasi hubungan antar pasar konsumen dapat diihat pada Tabel 5.

Tabel 5. Hasil Uji akar Unit (DF Test level I(0)) Residual Persamaan Kointegrasi Hubungan antar Pasar Konsumen

\begin{tabular}{|c|c|c|c|c|}
\hline${ }_{\text {Dari }} \mathrm{Ke}$ & Panorama & Minggu & Ampera & Purwodadi \\
\hline Panorama & & $-9,0225^{\star * *}$ & $-10,0048^{* * *}$ & $-9,6060^{* * *}$ \\
\hline Minggu & $-8,0515^{* * *}$ & & $-7,6903^{* * *}$ & $-7,2977^{* * *}$ \\
\hline Ampera & $-8,2313^{* * *}$ & $-9,0327 * * *$ & & $-7,5190^{* * *}$ \\
\hline Purwodadi & $-8,5496^{* * *}$ & $-9,1520 * * *$ & $-7,9680 * * *$ & \\
\hline \multirow[t]{2}{*}{ Nilai Kritis } & \multicolumn{2}{|c|}{$1 \%$} & \multicolumn{2}{|c|}{$-3,5300$} \\
\hline & \multicolumn{2}{|c|}{$5 \%$} & \multicolumn{2}{|c|}{$-2,9048$} \\
\hline
\end{tabular}

Sumber : Hasil Analisis Data Sekunder (2011)

Keterangan ${ }^{* * *}$ Signifikan pada a $1 \%$ dan ${ }^{* *}$ Signifikan pada a $5 \%$

Dari hasil estimasi keterpaduan pasar antar pasar Panorama dan Minggu diperoleh nilai t-statistik $(-9,0225)$ yang lebih besar dari nilai kritis MacKinnon (3,5300) pada tarap signifikansi (a) $1 \%$ sehingga akan menolak Ho dan menerima $\mathrm{H} 1$ yang berarti rangkaian data harga dan rangkaian residu pada persamaan kointegrasi adalah stasioner pada tarap kepercayaan 99\%, artinya terdapat keterpaduan pasar yang kuat pada kombinasi pasar tersebut. Tingkat keterpaduan pasar yang kuat menunjukkan bahwa ada hubungan antar pasar 
tersebut dalam perubahan harga dan transmisi harga sehingga naik turunnya harga cabai merah keriting di salah satu pasar akan berpengaruh terhadap kedua pasar tersebut. Jarak pasar yang dekat menjadi salah satu indikator keterpaduan pasar tersebut. Selain itu, informasi pasar dapat diketahui dengan jelas dikarenakan faktor jarak yang dekat tersebut sehingga akan terjadi keterpaduan pasar yang kuat antar pasar konsumen tersebut.

Sama halnya dengan pasar Panorama dan Minggu, keterpaduan pasar Minggu dan Panorama (-8,0515 > -3,5300) yang kuat juga diakibatkan jarak pasar yang dekat dan informasi pasar yang mudah diperoleh sehingga akan terjadi keterpaduan pasar yang kuat antar pasar konsumen tersebut. Tingkat keterpaduan pasar yang kuat juga terjadi pada kombinasi pasar Panorama dan Ampera dengan nilai t-statistik $(-10,0048)$ yang lebih besar dari nilai kritis MacKinnon $(-3,5300)$ pada tarap signifikansi (a) $1 \%$ sehingga akan menolak Ho dan menerima $\mathrm{H} 1$ yang berarti rangkaian data harga dan rangkaian residu pada persamaan kointegrasi adalah stasioner pada tarap kepercayaan 99\%, artinya terdapat keterpaduan pasar yang kuat pada kombinasi pasar tersebut. Tingkat keterpaduan pasar yang kuat ini akan mempengaruhi dalam hal perubahan harga dan transmisi harga cabai merah keriting. Begitu juga dengan kombinasi pasar Panorama dengan pasar konsumen lainnya seperti pasar Minggu, Purwodadi dan Ampera ataupun sebaliknya, kombinasi pasar-pasar tersebut menunjukkan tingkat keterpaduan yang sama sehingga akan mempengaruhi dalam hal perubahan harga dan transmisi harga.

Pasar Panorama merupakan pasar konsumen yang menjembatani perdagangan komoditas pertanian seperti cabai merah keriting dari pasar sentra produksi Curup ke pasar konsumen lainnya. Jika pasar konsumen seperti pasar Ampera dan Purwodadi ingin membeli cabai merah keriting harus melalui pasar Panorama, maka naik turunnya harga cabai merah keriting di pasar Panorama akan mempengaruhi harga di pasar lain yaitu Ampera dan Purwodadi.

Tingkat keterpaduan pasar yang kuat juga tejadi antara pasar Minggu dan Ampera dengan nilai t-statistik $(-7,6903)$ yang lebih besar dari nilai kritis MacKinnon $(-3,5300)$ pada tarap signifikansi (a) 1 \% sehingga akan menolak Ho dan menerima $\mathrm{H} 1$ yang berarti rangkaian data harga dan rangkaian residu pada persamaan kointegrasi adalah stasioner pada tarap kepercayaan 99\%, artinya terdapat keterpaduan pasar yang kuat pada kombinasi pasar tersebut. Hal ini menunjukkan adanya hubungan saling mempengaruhi dalam perubahan harga dan transmisi harga di pasar-pasar tersebut. Tingkat keterpaduan pasar yang kuat juga terjadi pada kombinasi pasar Ampera dan Minggu (-9,0327 > -3,5300) sehingga perubahan harga pada salah satu pasar akan saling mempengaruhi. Selain itu tingkat keterpaduan pasar yang kuat juga terjadi pada kombinasi pasar Minggu dan Purwodadi $(-7,2977>-3,5300)$ ataupun sebaliknya antara kombinasi pasar Purwodadi dan Minggu (-9,1520 > -3,5300), sehingga akan mempengaruhi dalam perubahan harga dan transmisi harga. Hal ini dapat terjadi karena komoditas cabai merah keriting diperoleh dari sentra produksi 
yang sama dan dibeli dari tempat yang sama sehingga perubahan harga di masing-masing pasar tersebut akan saling mempengaruhi.

\section{Uji Granger Causality}

Uji kausalitas yang digunakan di dalam penelitian ini adalah uji Granger Causality. Uji kausalitas akan dilakukan yaitu terhadap pasar produsen yaitu pasar Curup dan pasar konsumen yaitu pasar Panorama, Minggu, Ampera dan Purwodadi. Uji kausalitas ini bertujuan untuk mengetahui hubungan sebab akibat antara dua pasar. Dari hasil analisis hubungan kausalitas akan diketahui pasar pemimpin komoditas cabai merah keriting di Propinsi Bengkulu. Pasar dikatakan pemimpin jika dominan dalam penentuan harga.

Dari hasil uji Granger Causality berdasarkan uji F (Tabel 6) terhadap Pasar produsen Curup dan pasar konsumen Panorama, Minggu dan Purwodadi. Pasar Curup dan pasar Panorama mempunyai hubungan kausalitas dua arah (FStatistik Curup-Panorama $=4,2325$ dan FStatistik Panorama-Curup $=6,8793$ ) dan saling mempengaruhi dengan pasar Panorama sebagai pasar pemimpinnya (Dilihat dari nilai FStatistik Panorama-Curup 6,8793 > FStatistik CurupPanorama 4,2325). Hal ini menggambarkan bahwa respon perubahan harga di pasar Curup dapat diterima dengan baik oleh pasar Panorama, maupun sebaliknya respon perubahan harga di pasar Panorama juga dapat diterima dengan baik oleh pasar Curup. Waktu kelambanan untuk kedua pasar agar saling mempengaruhi yaitu selama satu bulan (dilihat dari nilai lags yaitu 1).

Tabel 6. Hasil Analisis Kausalitas (Granger Causality) antara Pasar Produsen dan Pasar Konsumen dan antar Pasar Konsumen

\begin{tabular}{|c|c|c|c|c|c|}
\hline Dari $\quad \mathrm{Ke}$ & $\begin{array}{l}\text { Pasar } \\
\text { Curup }\end{array}$ & $\begin{array}{c}\text { Pasar } \\
\text { Panorama }\end{array}$ & $\begin{array}{c}\text { Pasar } \\
\text { Minggu }\end{array}$ & $\begin{array}{c}\text { Pasar } \\
\text { Ampera }\end{array}$ & $\begin{array}{c}\text { Pasar } \\
\text { Purwodadi }\end{array}$ \\
\hline Pasar Curup & & $4,2325^{* * a}$ & $0,0038 \mathrm{~ns}$ & $1,0255 \mathrm{~ns}$ & $0,1658 \mathrm{~ns}$ \\
\hline Pasar Panorama & $6,8793^{* *_{a}}$ & & $1,6068 \mathrm{~ns}$ & $5,7587^{* * * *_{c}}$ & $8,1132^{* * * a}$ \\
\hline Pasar Minggu & $11,8206^{* * * a}$ & $6,7217^{* * a}$ & & $5,6694^{* * a}$ & $0,2985 \mathrm{~ns}$ \\
\hline Pasar Ampera & $1,0165 \mathrm{~ns}$ & $5,5921^{* * *_{c}}$ & $0,0871 \mathrm{~ns}$ & & $0,7478 \mathrm{~ns}$ \\
\hline $\begin{array}{l}\text { Pasar } \\
\text { Purwodadi }\end{array}$ & $9,2544^{* * *_{a}}$ & $0,3466 \mathrm{~ns}$ & $\begin{array}{l}6,3288^{* *} \\
\text { a }\end{array}$ & $10,5572^{* * * b}$ & \\
\hline
\end{tabular}

Sumber : Hasil Analisis Data Sekunder (2011)

Keterangan: a : Lags 1, b : Lags 2, c : Lags 3, ns Non Signifikan (tidak ada hubungan), *** Signifikan pada a $1 \%$, dan ** Signifikan pada a $5 \%$

Untuk pasar Curup dan pasar Minggu mempunyai hubungan satu arah (FStatistik Curup-Minggu $=0,0038$ ns (Non Signifikan) dan FStatistik MingguCurup $=11,8206$ ) dengan pasar Minggu sebagai pasar pemimpinnya (dilihat dari FStatistik Minggu-Curup = 11,8206 yang signifikan), respon perubahan harga di pasar Curup dapat diterima dengan baik oleh pasar Minggu. Respon perubahan harga tersebut dapat diterima dengan baik oleh pasar Minggu dengan waktu kelambanan yaitu selama satu bulan (dilihat dari nilai lags yaitu 
1). Pasar Curup dan pasar Purwodadi juga mempunyai hubungan satu arah dengan pasar Purwodadi sebagai pasar pemimpinnya (FStatistik CurupPurwodadi $=0,1658 \mathrm{~ns}$ (Non Signifikan) dan FStatistik Purwodadi-Curup = 9,2544), sehingga respon perubahan harga di pasar Curup dapat diterima dengan baik oleh pasar Purwodadi. Respon perubahan harga tersebut dapat diterima dengan baik dengan waktu kelambanan yaitu selama satu bulan (dilihat dari nilai lags yaitu 1). Sedangkan untuk pasar Ampera tidak terjadi hubungan sama sekali dengan pasar Curup (FStatistik Curup-Ampera = 1,0255ns (Non Signifikan) dan FStatistik Ampera-Curup $=1,0165 \mathrm{~ns}$ (Non Signifikan)) sehingga respon perubahan harga tidak diterima dengan baik oleh kedua pasar tersebut.

Selanjutnya pada kombinasi antar pasar konsumen, pasar Panorama dan pasar Ampera mempunyai hubungan dua arah $($ FStatistik Panorama-Ampera $=$ 5,7587 dan FStatistik Ampera-Panorama =5,5921) dan saling mempengaruhi dengan pasar Panorama sebagai pasar pemimpinnya (dilihat FStatistik Panorama-Ampera $=5,7587>$ FStatistik Ampera-Panorama $=5,5921)$. Hal ini menggambarkan bahwa respon perubahan harga di pasar Panorama dapat diterima dengan baik oleh pasar Ampera, maupun sebaliknya respon perubahan harga di pasar Ampera juga dapat diterima dengan baik oleh pasar Panorama. Waktu kelambanan untuk kedua pasar agar saling mempengaruhi yaitu selama tiga bulan (dilihat dari nilai lags yaitu 3). Sedangkan, pasar Panorama dan pasar Purwodadi memiliki hubungan satu arah (FStatistik Panorama-Purwodadi $=$ 8,1132 dan FStatistik Purwodadi-Panorama $=0,3466$ ns (Non Signifikan)) dengan pasar Panorama sebagai pasar pemimpinnya (dilihat dari FStatistik PanoramaPurwodadi $=8,1132$ yang signifikan), respon perubahan harga di pasar Purwodadi dapat diterima dengan baik oleh pasar Panorama. Respon perubahan harga tersebut dapat diterima dengan baik oleh pasar Panorama dengan waktu kelambanan yaitu selama satu bulan (dilihat dari nilai lags yaitu 1).

Pasar Panorama dan Minggu mempunyai hubungan satu arah (FStatistik Minggu-Panorama $=6,7217$ dan FStatistik Panorama-Minggu $=1,6068 \mathrm{~ns}$ (Non Signifikan)) namun berbeda dengan kombinasi pasar sebelummya, pasar pemimpin pada kombinasi pasar ini yaitu pasar Minggu (dilihat dari FStatistik Minggu-Panorama $=6,7217$ yang signifikan). Respon perubahan harga di pasar Panorama dapat diterima dengan baik oleh pasar Minggu dengan waktu kelambanan yaitu selama satu bulan (dilihat dari nilai lags yaitu 1). Pasar Minggu dan pasar Ampera juga mempunyai hubungan satu arah (FStatistik Minggu-Ampera $=5,6694$ dan FStatistik Ampera-Minggu $=0,0871 \mathrm{~ns}$ (Non Signifikan)) dengan pasar Minggu sebagai pasar pemimpinnya (dilihat dari FStatistik Minggu-Ampera = 5,6694 yang signifikan). Respon perubahan harga di pasar Ampera dapat diterima dengan baik di pasar Minggu dengan waktu kelambanan yaitu selama satu bulan (dilihat dari nilai lags yaitu 1 ).

Pasar Purwodadi dan pasar Minggu mempunyai hubungan satu arah (FStatistik Purwodadi-Minggu $=6,3288$ dan FStatistik Minggu-Purwodadi $=$ 0,2985ns (Non Signifikan)) dengan pasar Purwodadi sebagai pasar 
pemimpinnya (dilihat dari FStatistik Purwodadi-Minggu $=6,3288$ yang signifikan). Respon perubahan harga di pasar Minggu dapat diterima dengan baik oleh pasar Purwodadi dengan waktu kelambanan yaitu selama satu bulan (dilihat dari nilai lags yaitu 1). Pasar Purwodadi dan pasar Ampera juga mempunyai hubungan satu arah (FStatistik Purwodadi-Ampera $=10,5572$ dan FStatistik Ampera-Purwodadi $=0,7478 \mathrm{~ns}$ (Non Signifikan)) dengan pasar Purwodadi sebagai pasar pemimpinnya (dilihat dari FStatistik PurwodadiAmpera $=10,5572$ yang signifikan). Respon perubahan harga di pasar Ampera dapat diterima dengan baik oleh pasar Purwodadi dengan waktu kelambanan yaitu selama dua bulan (dilihat dari nilai lags yaitu 2).

Dari hasil uji Granger Causality pada Tabel 6, diketahui bahwa pasar Panorama mendominasi sebagian besar pasar cabai merah keriting di Propinsi Bengkulu dan menjadi pasar pemimpin di pasar-pasar tersebut. Hal ini dikarenakan pasar ini merupakan pasar konsumen yang juga sebagai pasar pemasok cabai merah keriting dari sentra produksi ke daerah lainnya di Propinsi Bengkulu sehingga konsepnya mirip dengan daerah produsen. Berkaitan dengan hipotesis ketiga diduga bahwa pasar komoditas cabai merah keriting dalam hal penentuan harga didominasi (Pasar Pemimpin) oleh pasar produsen yaitu pasar produsen Curup. Dari Tabel tersebut diketahui pasar yang dominan dalam hal penentuan harga adalah pasar konsumen Panorama yang memimpin pasar produsen Curup dan pasar konsumen Ampera dan Purwodadi sehingga hipotesis tidak diterima. Hal ini dapat dilihat dari respon perubahan harga di pasar Curup, Ampera dan Purwodadi dapat diterima dengan baik oleh pasar Panorama.

\section{SIMPULAN DAN SARAN}

\section{Simpulan}

Berdasarkan hasil penelitian tentang "Analisis Perilaku Harga dan Keterpaduan Pasar Cabai Merah Keriting (Capsicum annuum) di Propinsi Bengkulu" dapat disimpulkan bahwa :

1. Perilaku harga cabai merah keriting di Propinsi Bengkulu adalah relatif berfluktuasi. Nilai koefisien variasi (KV) di pasar konsumen $(\mathrm{KV}=42,35 \%)$ lebih kecil dibandingkan nilai KV di pasar produsen $(\mathrm{KV}=64,41 \%)$. Hal ini menunjukkan bahwa harga cabai merah keriting di pasar konsumen relatif stabil dibandingkan dengan harga di pasar produsen, dengan kata lain bahwa harga cabai merah keriting di pasar produsen lebih berfluktuasi dari pada harga di pasar konsumen.

2. Dalam pemasaran cabai merah keriting di Propinsi Bengkulu terdapat keterpaduan pasar dalam pembentukan harga baik antara pasar produsen dan pasar konsumen maupun antar pasar konsumen dengan tingkat keterpaduan yang kuat. Tingkat keterpaduan pasar yang kuat terjadi antara pasar produsen Curup dan pasar konsumen Panorama, Minggu, Ampera 
dan Purwodadi. selain itu tingkat keterpaduan pasar yang kuat juga terjadi antar pasar konsumen yaitu antar pasar konsumen Panorama, Minggu, Ampera dan Purwodadi.

3. Pasar pemimpin untuk pasar komoditas cabai merah keriting di Propinsi Bengkulu adalah pasar konsumen Panorama.

\section{Saran}

Mengingat arti pentingnya komoditas cabai merah keriting bagi produsen yaitu petani dan masyarakat sebagai konsumen, maka perlu ada peran pemerintah untuk membuat kebijakan yang berkaitan dengan pemasaran cabai merah keriting sehingga dapat meningkatkan kesejahteraan baik produsen maupun konsumennya. Kebijakan tersebut diantaranya yaitu perlu ditingkatkan pengaturan saat tanam antar wilayah produksi dan penstabilan pasokan cabai merah keriting di Propinsi Bengkulu, tujuannya untuk mengurangi fluktuasi harga cabai merah keriting di Propinsi Bengkulu. Selain itu, pemerintah harus memberikan informasi tentang harga cabai merah keriting baik di media cetak, radio ataupun media televisi, agar petani sebagai produsen dan masyarakat sebagai konsumen mengetahui informasi harga cabai merah keriting tersebut.

\section{DAFTAR PUSTAKA}

Anindita, R. 2004. Pemasaran Hasil Pertanian. Papyrus. Surabaya.

[BPS]. 2011. Luas Panen, Produksi dan Produktivitas Cabai Merah Menurut Kabupaten/Kota Di Propinsi Bengkulu Pada Tahun 2010. Data Base, Badan Pusat Statistik Propinsi Bengkulu. Bengkulu.

Engle, R. F dan C. W. J. Granger. 1987. Co-Integration and Error Corection : Representation, Estimation, and Testing. Econometrica 55:251-276.

Fadhla, T. 2008. Integrasi Pasar Komoditas Pangan (Beras, Kacang Tanah Kupas dan Kedelai Kuning) Di Propinsi Nangroe Aceh Darussalam. Jurnal Agritek 16(9): 1632 - 1655.

Nazir, M. 2003. Metode Penelitian. Ghalia Indonesia. Jakarta.

Nidausoleha, O. 2007. Analisis Perilaku Harga dan Keterpaduan Pasar Komoditas Bawang Merah Di Jawa. Tesis Sekolah Pascasarjana Universitas Gadjah Mada. Yogyakarta.

Santoso, S. 2003. Statistik Diskriptif Konsep dan Aplikasi dengan Microsoft Excel dan SPSS. ANDI. Yogyakarta.

Widarjono, A. 2007. Ekonometrik: Teori dan Aplikasi untuk Ekonomi dan Bisnis, Edisi Kedua. EKONISIA. Yogyakarta.

Winarno, W.W. 2009. Analisis Ekonometrika dan Statistika dengan Eviews(Edisi Kedua). UPP STIM YKPN. Yogyakarta. 